\title{
POLYCRYSTALLINE FIBROUS DIAMONDS FROM THE DIAVIK DIAMOND MINE, CANADA
}

\author{
Hunt L. ${ }^{1 *}$, Stachel T. ${ }^{1}$, Pearson D.G. ${ }^{1}$, Stern R. ${ }^{1}$, Muehlenbachs, K. ${ }^{1}$, \\ McLean H. ${ }^{2}$ and Marcheggiani-Croden V. ${ }^{1}$ \\ 1. Department of Earth and Atmospheric Sciences, University of Alberta, Canada \\ 2. Rio Tinto, Diavik Diamond Mines Inc., Yellowknife, Canada \\ * Corresponding author email address: lchunt@ualberta.ca
}

\section{INTRODUCTION}

The Diavik Diamond Mine is located in the Cretaceous-Miocene Lac de Gras Kimberlite Field of the Central Slave craton (Fig. 1). Whilst high value gem diamonds strongly dominate, fibrous/ polycrystalline overgrowths on crystalline diamonds, opaque fibrous cubes and polycrystalline boart are also common, and are detrimental to production value. Research has concentrated on the gem quality diamonds and their inclusions, and little is known to date about the origin of fibrous and polycrystalline diamonds/ coats. Using a multi-technique approach this research focuses on non-gem diamonds from Diavik, with the aim to establish their origin and to determine the changes in physical and chemical conditions which accompany the transition from gem to non-gem diamond growth.

\section{SAMPLES}

After careful sorting through $\sim 10,000$ carats of diamonds, around 600 diamonds were selected for this study. The samples collected included: A suite of polycrystalline/fibrous diamonds; diamonds intergrown with other minerals; coated diamonds; and diamonds with polycrystalline cores. Special care was taken to ensure that all these suites contained samples of different morphologies (e.g. octahedral, dodecahedral and cuboid). The majority were from the +11 and +9 size fractions $(\sim 3-7 \mathrm{~mm}$ and $\sim 1.5-3 \mathrm{~mm}$ diameter, respectively).

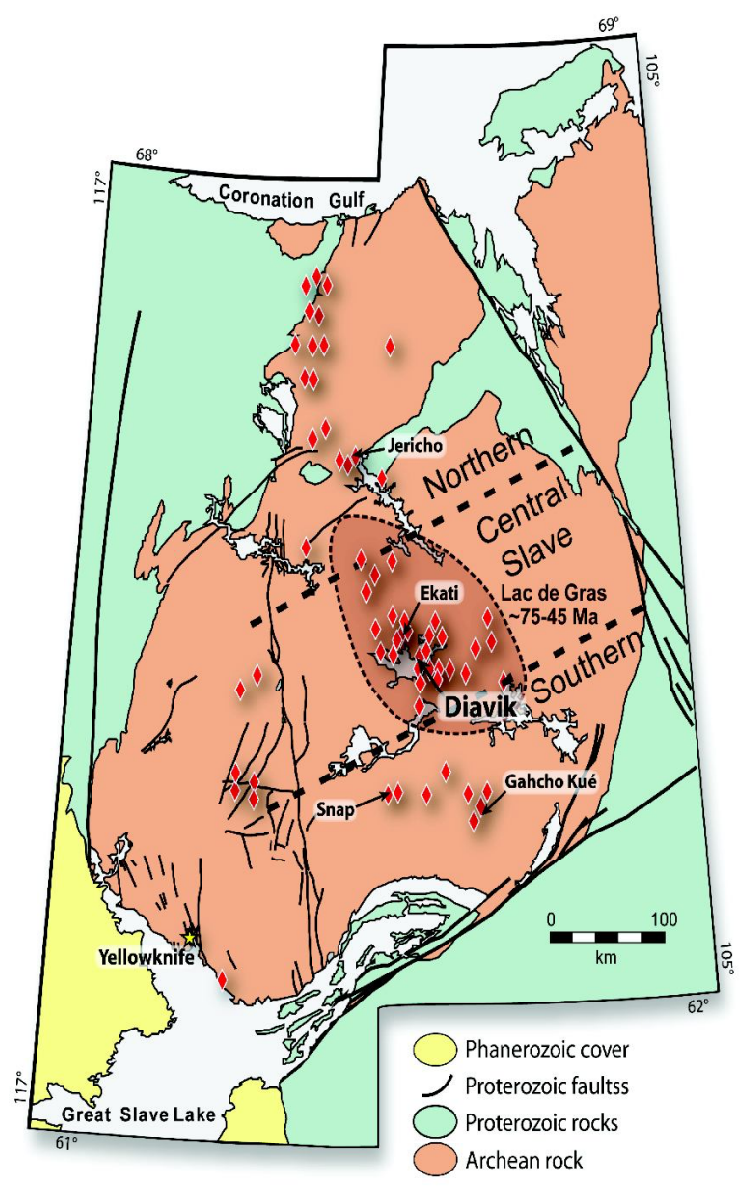

Figure 1. Simplified geological map of the Slave craton, showing the location of the Diavik diamond mine and the major diamond producing kimberlites. Redrawn from the compilation of Bleeker and Hall (2007). 


\section{$1^{\text {th }}$ International Kimberlite Conference, Bangalore - 2012}

\section{TECHNIQUES}

Initially, the diamonds were visually described and a subset of polycrystalline and fibrous diamonds selected. These stones will be laser sectioned and polished into plates for Fourier Transform Infrared (FTIR) spectroscopy and secondary ion mass spectrometry (SIMS) analysis to determine their nitrogen contents and aggregation states and their carbon isotopic compositions.

To help derive the nature and evolution of the diamond's precipitating fluid/melt it is of particular interest whether these parameters change across boundaries separating gem and nongem growth, and within individual growth sectors e.g. across coats. To explore this, the SIMS carbon isotopic and nitrogen content analyses will be along transects perpendicular to growth planes with a point spacing of $\sim 30-100 \mathrm{im}$. Conventional analysis of carbon isotopes involves the combustion of larger portions of diamond which average a number of growth horizons. The SIMS technique has shown micro-scale variations of $\ddot{a}^{13} \mathrm{C}$ and $\mathrm{N}$ content, allowing for more detailed growth mechanism interpretations.

\section{CATHODOLUMINESCENCE IMAGING}

Initially, five non-gem diamonds have been sectioned, mounted and imaged using cathodoluminescence (CL), and will shortly be analysed by SIMS. The CL images show fine scale complexities in strongly clouded diamond growth that are not observed under the microscope (Figs. 2 and 3 ). Luminescence is caused by point defects in the diamond, such as impurities (e.g. Wilks and Wilks, 1991 and references therein). This observed zoning is likely due to differences in nitrogen content, the main source and also the principal quencher (particularly A-centres) to luminescence in a diamond (e.g., Wight et al., 1971).

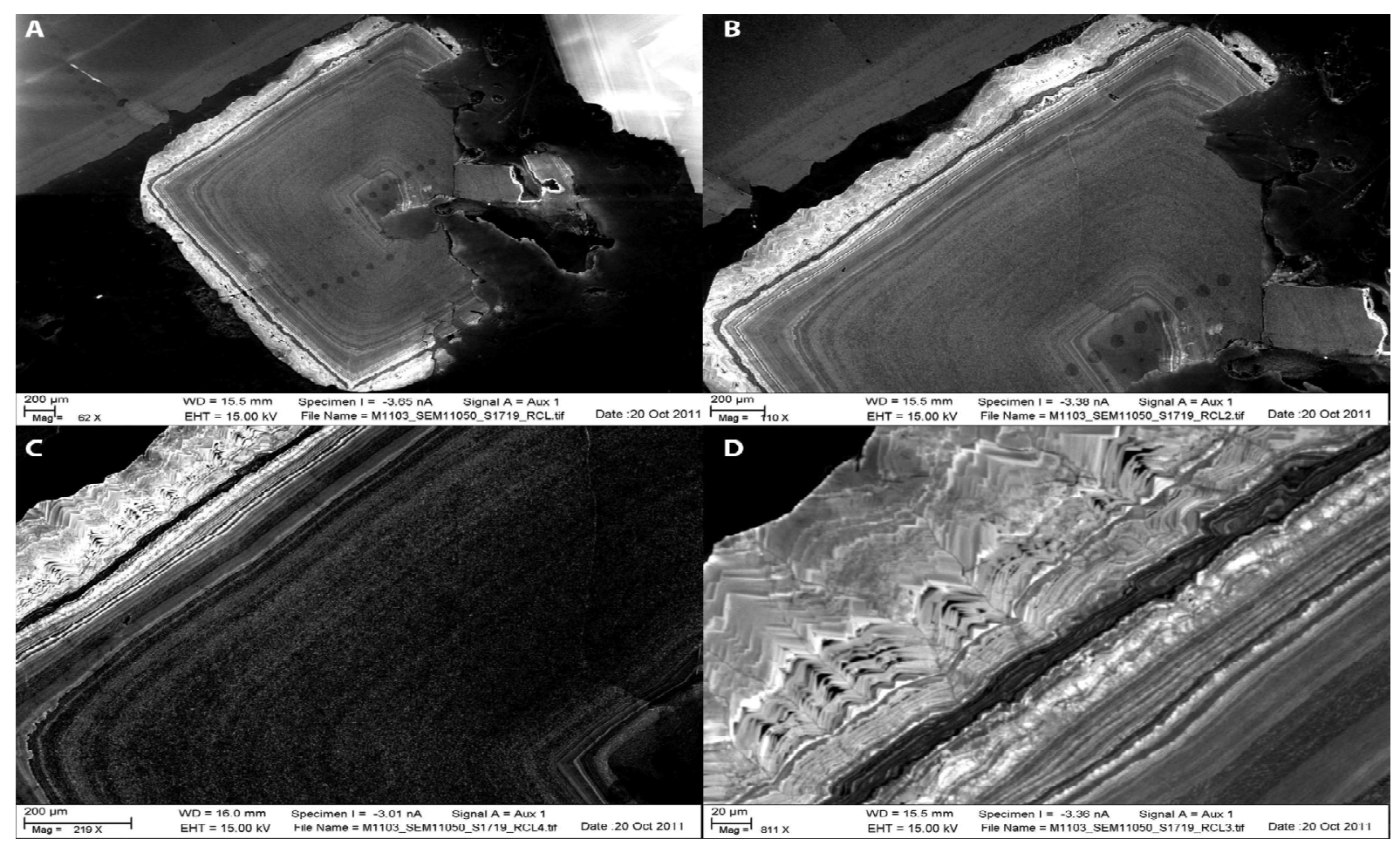

Figure 2. Cathodoluminescence images of a hailstone boart cube. 


\section{$1^{\text {th }}$ International Kimberlite Conference, Bangalore - 2012}

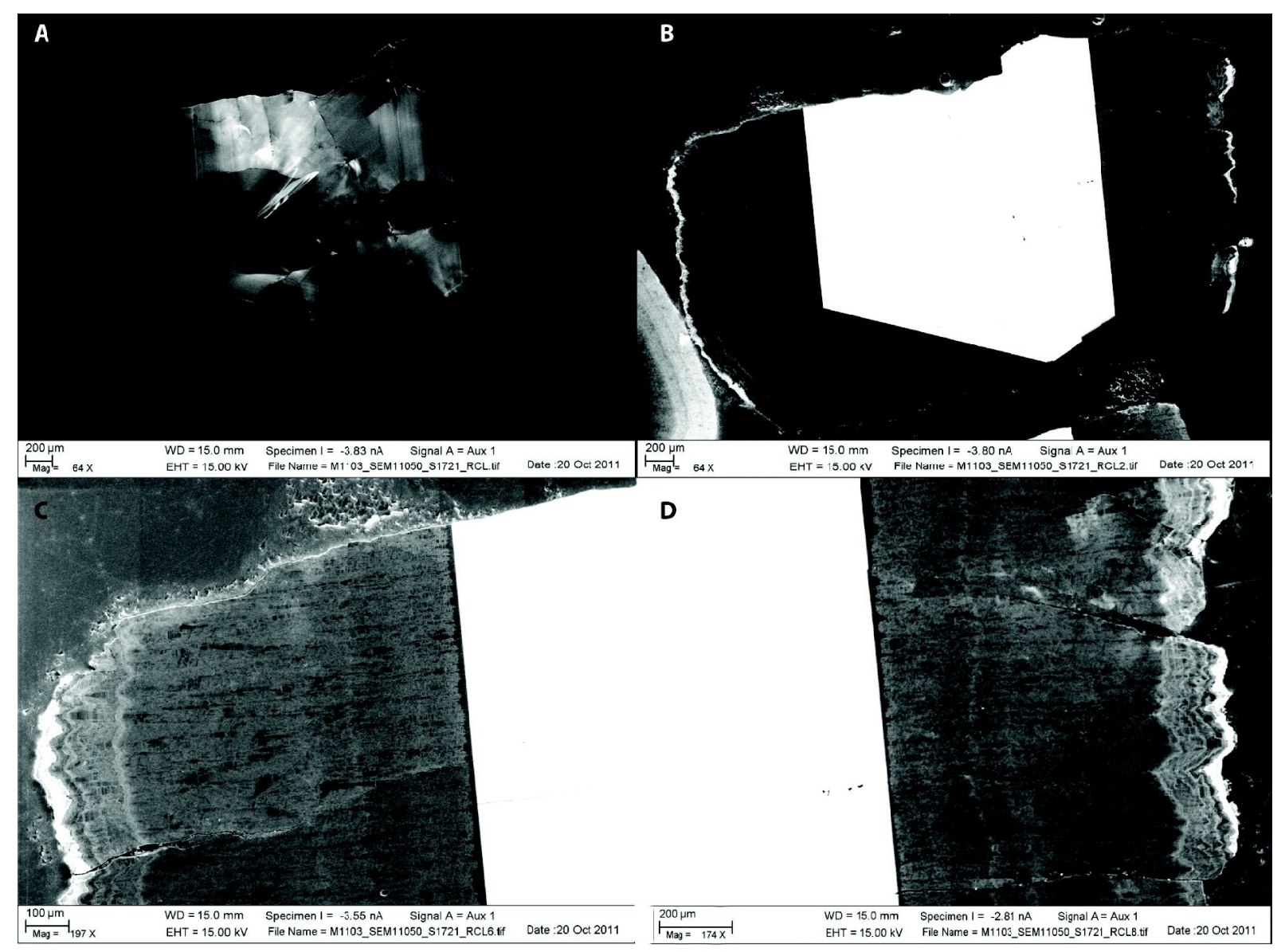

Figure 3. Cathodoluminescence images of a coated octahedral diamond fragment.

Figure 2 shows the CL image of a $\sim 2.5 \mathrm{~mm}$ hailstone boart diamond. The centre of the stone is more homogeneous with one more extended growth event. The majority of the stone shows concentric growth rings, similar to tree rings. The outer $\sim 200 \mu \mathrm{m}$ has much more complex growth (Fig. 2d). This rim portion of the diamond appears to have grown in the octahedral $\{111\}$ directions, forming trigonal layers, at $45^{\circ}$ to the cube faces.

Figure 3 is a $\sim 4 \mathrm{~mm}$ fragment of a coated octahedral stone. Figures $3 \mathrm{a}$ and $3 \mathrm{~b}$ display the need for taking multiple CL images at different contrasts and brightnesses, with the central gem diamond being far more luminescent than the coat.
The octahedral gem portion of the diamond displays complex zoning and growth patterns, with a sharp boundary to the outer fibrous coat. The coat shows complex growth, simultaneously depicting outward radiating fibrous growth and concentric zoning. A thin band $(\sim 20 \mu \mathrm{m})$ of darker growth, in the CL image, is visible next to the gem diamond core. The outer $\sim 200 \mu \mathrm{m}$ shows irregular concentric banded growth and is more luminescent.

This pattern of more regular concentric growth, followed by an outer $\sim 200 \mu \mathrm{m}$ of more irregular growth is present in all of the five samples mounted for SIMS. 


\section{$1^{\text {th }}$ International Kimberlite Conference, Bangalore - 2012}

\section{LARGE (54 CARAT) DIAVIK BOART}

Fibrous/polycrystalline diamonds/coats are commonly assumed to have precipitated during distinct diamond forming events (e.g. Klein BenDavid et al., 2007; Jacob et al., 2011), characterised by high levels of supersaturation. They are often closely associated in time with kimberlite magmatism (e.g. Janson et al., 2008; Araujo et al., 2009, although isotopic studies (Klein BenDavid et al., 2010) show that some fibrous diamonds clearly form from a mixed fluid source, with both asthenospheric and lithospheric origins. The relationship of polycrystalline diamond aggregates to fibrous coats and hailstone boart is not clear.

Preliminary research has been conducted on a 54 carat piece of Diavik boart (Fig. 4) with intergrown silicate minerals of predominantly garnet and clinopyroxene. Carbon isotopic

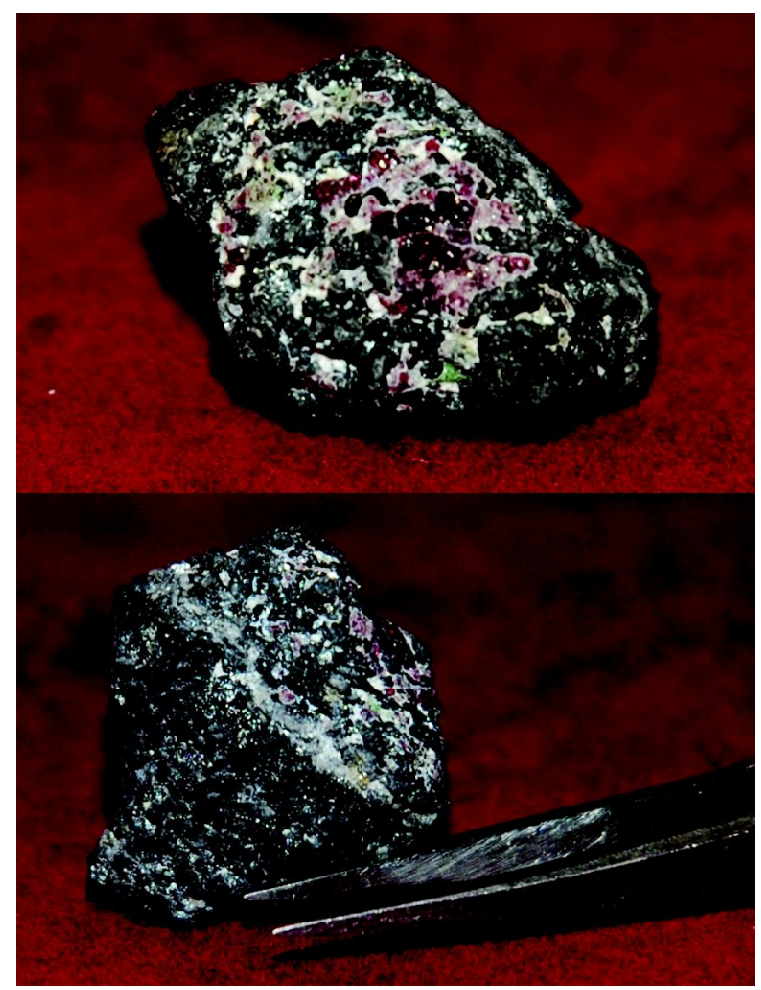

Figure 4. .54 carat piece of boart with intergrown garnet and clinopyroxene minerals. analyses were performed by conventional sealed tube combustion technique, on samples taken from a number of growth horizons across the stone. The boart diamond appears to be isotopically homogeneous throughout, with a narrow range of $\ddot{a}^{13} \mathrm{C}$ values from -23.4 to $-23.8 \%$.

Such ${ }^{13} \mathrm{C}$ depleted compositions are typically associated with an eclogitic or websteritic paragenesis. However, the intergrown silicate phases document an unusually fertile lherzolitic paragenesis. The garnets are lower in $\mathrm{Cr}_{2} \mathrm{O}_{3}$ ( $\sim 4 \mathrm{wt} \%)$ and generally higher in $\mathrm{TiO}_{2}(\sim 0.27 \mathrm{wt} \%)$ than typical harzburgitic garnet inclusions in gem diamonds from the same locality (Donnelly et al., 2007). Clinopyroxene in the boart has $\mathrm{Cr}_{2} \mathrm{O}_{3}$ contents comparable to inclusions in Diavik gem diamonds. The analysed silicate minerals indicate an origin of $\sim 1210^{\circ} \mathrm{C}$ and $59 \mathrm{kbar}$, as compared to $1190^{\circ} \mathrm{C}, 52 \mathrm{kbar}$ for diamond inclusions (Donnelly et al., 2007) and $1010^{\circ} \mathrm{C}$ and $48 \mathrm{kbar}$ for diamondiferous lherzolitic microxenoliths (Creighton et al., 2008).

These data suggest that the boart sample may relate to interaction of a subduction derived fluid/ melt, characterised by low $\delta^{13} \mathrm{C}$ with a mantle peridotite.

\section{CONCLUSIONS}

Based on this preliminary data set, the complex nature of polycrystalline growth is evident. Cathodoluminescence images of hailstone boart and coated diamonds show complex concentric rings of growth, likely related to differences in nitrogen contents.

Due to the carbon isotopic composition of a 54 carat boart diamond, and the composition of the intergrown silicate minerals, it is suggested that at least a portion of the non-gem diamond growth at Diavik may be related to the interaction of a subduction derived fluid/melt with the peridotitic mantle. Thermobarometric data imply that this occurred close to or at the base of the lithosphere $(\sim 180 \mathrm{~km})$. 


\section{0 $^{\text {th }}$ International Kimberlite Conference, Bangalore - 2012}

\section{References}

Araujo D.P., Griffin W.L., O’Reilly S.Y., Grant K.J., Ireland T., Holden P. and van Achterbergh E., 2009. Microinclusions in monocrystalline octahedral diamonds and coated diamonds from Diavik, Slave Craton: Clues to diamond genesis. Lithos, 112 (supplement 2), 724-735.

Bleeker W., Hall B., 2007. The Slave Craton: geology and metallogenic evolution. In: Goodfellow, W.D. (Ed.), Mineral Deposits of Canada: A Synthesis of Major Deposit- Types, District Metallogeny, the Evolution of Geological Provinces, and Exploration Methods: Geological Association of Canada, Mineral Deposits Division: Special Publication, vol. 5, pp. 849-879.

Creighton S., Stachel T., McLean H., Muehlenbachs K., Simonetti A., Eichenberg D. and Luth R., 208. Diamondiferous peridotitic microxenoliths from the Diavik Diamond Mine, NT. Contributions to Mineralogy and Petrology, 155(5), 541-554.

Donnelly C.L., Stachel T., Creighton S., Muehlenbachs K. and Whiteford S., 2007 - Diamonds and their mineral inclusions from the A154 South pipe, Diavik Diamond Mine, Northwest territories, Canada. Lithos, 98, 160-176

Jacob D.E., Wirth R., Enzmann F., Kronz A. and Schreiber A., 2011. Nano-inclusion suite and high resolution micro-computed-tomography of polycrystalline diamond (framasite) from Orapa, Botswana. Earth and Planetary Science Letters, 308 (3-4), 307-316.

Janson G., Muehlenbachs K., Stachel T. and Eichenberg D., 2008. Carbon isotope variations across diamonds with clear and opaque growth zones measured by secondary ion mass spectrometry. 9th International Kimberlite Conference Extended Abstract No. 9IKC-A-00295.

Klein-BenDavid O., Pearson D.G., Nowell G.M., Ottley C.J., McNeill J.C.R. and Cartigny P. (2010). Mixed fluid sources involved in diamond growth constrained by constrained by $\mathrm{Sr}-\mathrm{Nd}-\mathrm{Pb}-\mathrm{C}-\mathrm{N}$ isotopes and trace elements. Earth and Planetary Science Letters. 289, 123-133

Klein-BenDavid O., Wirth R. and Navon O., 2007. Micrometre-scale cavities in fibrous and cloudy diamonds - a glance into diamond dissolution events. Earth and Planetary Science Letters, 264 (1-2), 89-103

Wilks J. and Wilks E.1991. Properties and Applications of Diamond. Butterworth-Heinemann, Oxford

Wight D.R., Dean P.J., Lightowlers E.C. and Mobsby C.D. 1971. Luminescence from natural and manmade diamond in the near infrared. Journal of Luminescence 4 (3), 169-193 